\title{
Totally laparoscopic pylorus-preserving gastrectomy for early gastric cancer in the middle stomach: technical report and surgical outcomes
}

\author{
Koshi Kumagai $\cdot$ Naoki Hiki $\cdot$ Souya Nunobe $\cdot$ Sayuri Sekikawa $\cdot$ \\ Takehiro Chiba $\cdot$ Takashi Kiyokawa $\cdot$ Xiaohua Jiang $\cdot$ Shinya Tanimura $\cdot$ \\ Takeshi Sano $\cdot$ Toshiharu Yamaguchi
}

Received: 22 July 2013/Accepted: 30 December 2013/Published online: 31 January 2014

(C) The International Gastric Cancer Association and The Japanese Gastric Cancer Association 2014

\begin{abstract}
Introduction The feasibility, safety, and improved quality of postoperative life following laparoscopy-assisted pylorus-preserving gastrectomy (LAPPG) with a hand-sewn anastomosis via a mini-laparotomy for early gastric cancer (EGC) have been previously established. Here we describe the surgical procedure of totally laparoscopic pylorus-preserving gastrectomy (TLPPG) using an intracorporeal delta-shaped anastomosis technique, and the short-term surgical outcomes of 60 patients with EGC in the middle stomach are reported.

Methods After lymphadenectomy and mobilization of the stomach, intraoperative gastroscopy was performed in order to verify the location of the tumor, and then the distal and proximal transecting lines were established, $5 \mathrm{~cm}$ from the pyloric ring and just proximal to Demel's line, respectively. Following transection of the stomach, a deltashaped intracorporeal gastrogastrostomy was made with linear staplers.

Results There were no intraoperative complications or conversions to open surgery. Mean operation time and blood loss were $259 \mathrm{~min}$ and $28 \mathrm{~mL}$, respectively. Twelve patients $(20.0 \%)$ experienced postoperative complications classified as grade II using the Clavien-Dindo
\end{abstract}

\footnotetext{
K. Kumagai · N. Hiki ( $₫) \cdot$ S. Nunobe $\cdot$ S. Sekikawa ·

T. Chiba $\cdot$ T. Kiyokawa $\cdot$ X. Jiang $\cdot$ S. Tanimura $\cdot$ T. Sano

T. Yamaguchi

Department of Gastroenterological Surgery, Cancer Institute

Hospital, Japanese Foundation for Cancer Research,

3-8-31 Ariake, Koto-ku, Tokyo 135-8550, Japan

e-mail: naoki.hiki@jfcr.or.jp

X. Jiang

Department of General Surgery, Zhongda Hospital,

Southeast University, Nanjing, China
}

classification, with the most frequent complication being gastric stasis (6 cases, $10.0 \%)$. The incidence of severe complications classified as grade III or above was $1.7 \%$; only one patient required reoperation and intensive care due to postoperative intraabdominal bleeding and subsequent multiple organ failure.

Conclusion TLPPG with an intracorporeal delta-shaped anastomosis was found to be a safe procedure, although it tended to require a longer operating time than the wellestablished LAPPG with a hand-sewn gastrogastrostomy.

Keywords Laparoscopic surgery · Gastrectomy · Pylorus · Postoperative complications

\section{Introduction}

Mortality associated with gastric cancer in Japan has decreased during recent decades. However, the incidence of early gastric cancer (EGC) is increasing due to a welldeveloped mass-screening program initiated by the government, and now accounts for over $50 \%$ of patients with gastric cancer [1,2]. EGC has a low recurrence rate and long survival time after surgical treatment; therefore, current research is focused on offering a better postoperative quality of life by developing function-preserving operations.

Pylorus-preserving gastrectomy (PPG) preserves the pyloric ring of the stomach, and was first performed by Miki et al. in 1967 [3]. This procedure was carried out successfully as an alternative treatment for gastric ulcers in an attempt to prevent postoperative dumping syndrome and bile reflux, conditions that were often seen after conventional distal gastrectomy with a Billroth-I anastomosis [36]. To date, laparoscopy-assisted PPG (LAPPG) with a hand-sewn gastrogastrostomy performed through a mini- 
laparotomy has been used to treat EGC and its safety and feasibility have been reported [7-12].

Several surgeons have also reported the safety and feasibility of the totally laparoscopic gastrectomy [13-15]. Compared with the laparoscopy-assisted procedure, the totally laparoscopic gastrectomy was found to be less invasive because it does not require a mini-laparotomy. Although some studies have compared the clinical outcomes of laparoscopy-assisted and totally laparoscopic gastrectomies, the feasibility of the totally laparoscopic gastrectomy remains unclear because of its technical difficulties [16].

Kanaya et al. [13] described a new, simple, easy, and safe technique for creating an intracorporeal delta-shaped gastroduodenostomy in laparoscopic distal gastrectomy. Similarly, Lee et al. [17] formed an intracorporeal deltashaped gastrogastrostomy during a laparoscopic segmental gastrectomy or PPG. Although an excellent surgical outcome was reported, the number of patients enrolled in the study was relatively small. Clinical evidence of the feasibility of using the delta-shaped anastomosis technique during PPG will encourage the use of totally laparoscopic PPG (TLPPG).

Herein we describe the surgical procedure of TLPPG using an intracorporeal delta-shaped anastomosis technique, and the short-term surgical outcomes are reported.

\section{Methods}

The indication for TLPPG was EGC located in the middle stomach, and intramucosal or submucosal carcinoma mostly without lymph node metastasis (cT1, cN0). Diagnosis of EGC was based on the preoperative assessment of the depth of wall invasion by gastroscopy, barium radiology, and endoscopic ultrasonography. Nodal involvement was determined by preoperative computed tomography. The study also included patients undergoing endoscopic mucosal resection or endoscopic submucosal dissection whose pathological results showed positive margins, submucosal tumor invasion, or tumor involvement of submucosal vessels. A distance of at least $7 \mathrm{~cm}$ was required between the distal margin of the tumor and the pyloric ring. For each patient, surgery was either performed or supervised by one of three experts in laparoscopic surgery (NH, SN, ST). Each expert consecutively applied TLPPG for eligible patients.

\section{Surgical procedures}

Mobilization of the stomach and D1+ lymphadenectomy were performed as previously described [18]. The lymph nodes at station 5 (suprapyloric) were routinely left intact.
The infrapyloric artery was routinely preserved to maintain a sufficient blood supply to the pyloric cuff, and the root of the right gastric artery was preserved and transected just distal to the first branch. The hepatic and pyloric branches of the vagus nerves were routinely preserved, and the celiac branch of the vagus nerve was preserved if possible.

After lymphadenectomy, intraoperative gastroscopy was routinely performed to verify the location of the tumor. The location of the preoperative marking clips, which were positioned during endoscopic examination a couple of weeks prior to surgery, was confirmed, and markings were made with dye prior to the dissection of the stomach. The distal transecting line was established $5 \mathrm{~cm}$ from the pyloric ring and the proximal transecting line was just proximal to Demel's line. The stomach was transected with 60-mm endoscopic linear staplers (ECHELON FLEX $^{\mathrm{TM}} 60$ ENDOPATH $^{\circledR}$ Stapler, 60-3.5; Ethicon Endo-Surgery, Cincinnati, OH, USA). The gastrectomy specimen was removed through the umbilical port site prior to the anastomosis.

The anastomosis was formed by inserting one arm of a 60-mm linear stapler through the gastrostomies on the greater curvature of each gastric remnant. The stapler was initially inserted into the proximal remnant and gradually shifted to the distal side. The stapler was then partially closed while the staple lines on the cut ends were brought together anteriorly by the operator and the assistant so that the anastomosis was formed between the posterior walls on either side (Fig. 1). Once fired, the stapler was removed and the remaining gastrostomy was closed by two further firings of the linear stapler over the free ends of the gastric

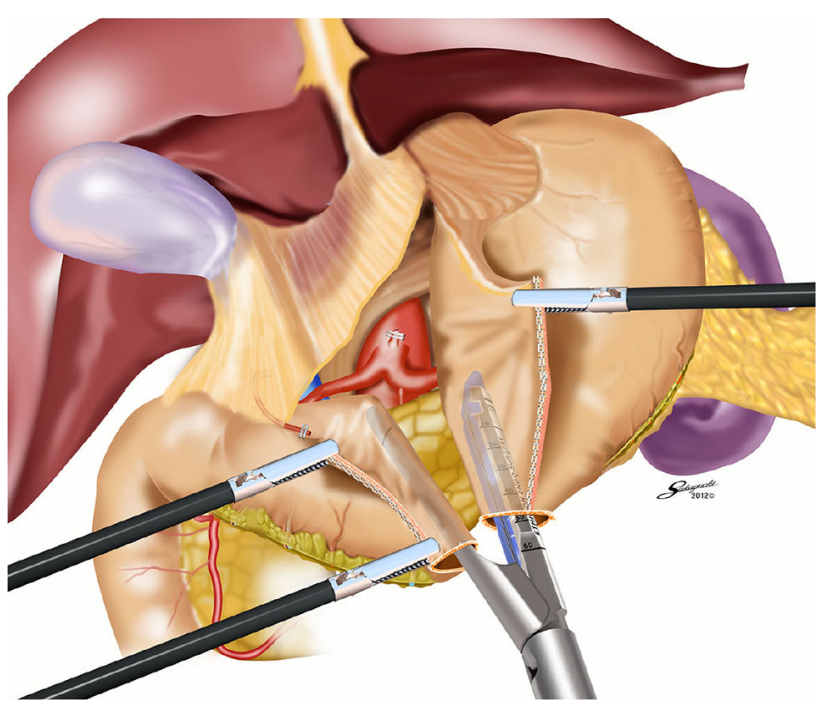

Fig. 1 The anastomosis was formed by inserting one arm of a $60-\mathrm{mm}$ linear stapler through the gastrostomies on the greater curvature of each gastric remnant. The stapler was partially closed while the staple lines on the cut ends were brought together anteriorly by the operator and the assistant so that the anastomosis was formed between the posterior walls on either side 


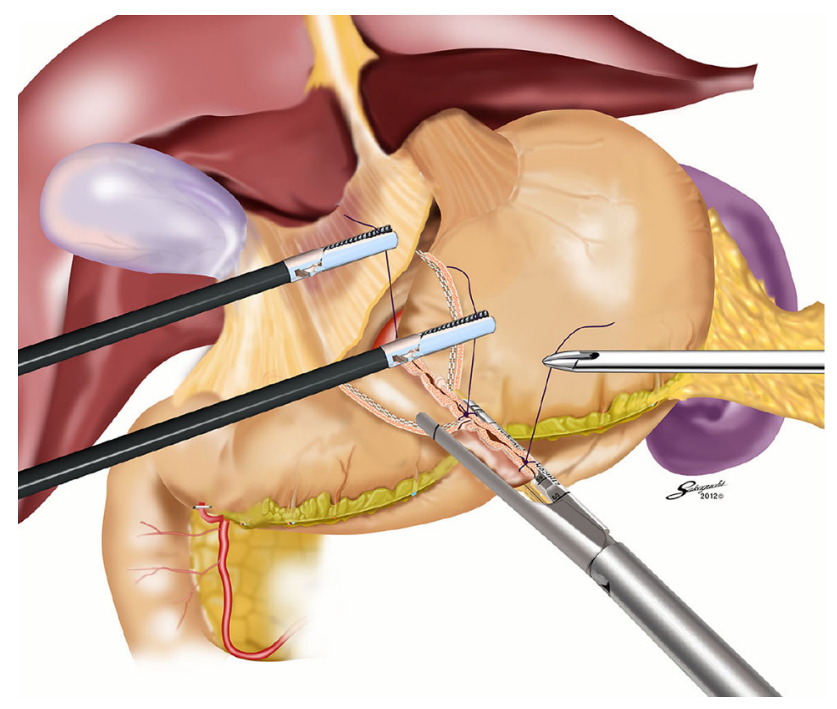

Fig. 2 The remaining gastrostomy was closed by two further firings of the linear stapler over the free ends of the gastric wall and three or four vertically opposed intracorporeal stay sutures

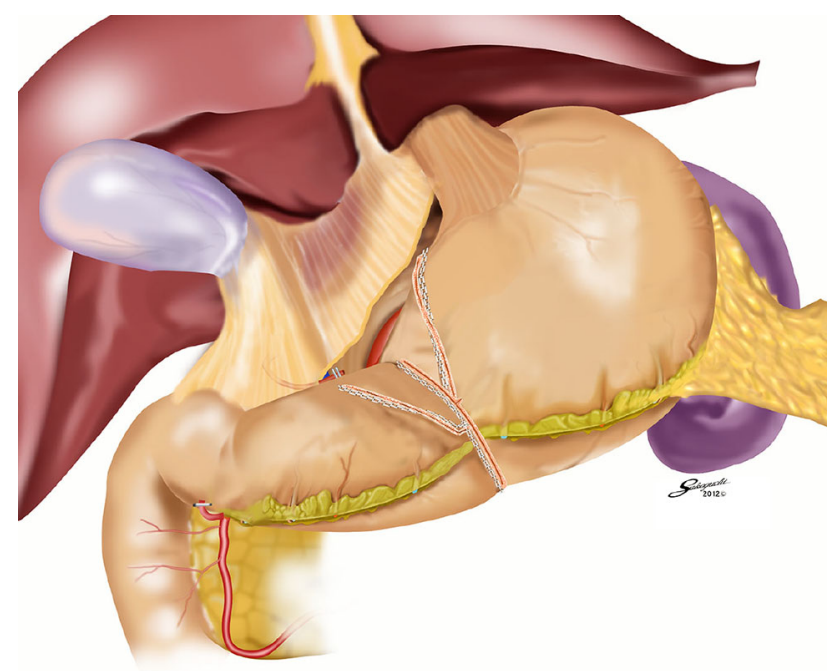

Fig. 3 After completing the anastomosis, the staple lines on the cut ends of the proximal and distal remnant stomach crossed almost perpendicularly to the staple lines that closed the gastrostomy

wall with three or four vertically opposed intracorporeal stay sutures (Fig. 2). After completing the anastomosis, the staple lines on the cut ends of the proximal and distal remnant stomach crossed almost perpendicularly to the staple lines that closed the gastrostomy (Fig. 3).

\section{Results}

From August 2010 to December 2011, TLPPG was performed in 60 patients with EGC. Characteristics of the patients are described in Table 1 and perioperative data are
Table 1 Characteristics of patients undergoing TLPPG $(n=60)$

\begin{tabular}{ll}
\hline Age (years) & $58.0[35-74]$ \\
Sex ratio (M:F) & $38: 22$ \\
ASA-PS $(1 / 2 / 3)$ & $36 / 24 / 0$ \\
Body mass index $\left(\mathrm{kg} / \mathrm{m}^{2}\right)$ & $22.2 \pm 3.0$ \\
Pretreatment (ESD) & $10(16.7 \%)$ \\
Previous laparotomy & $16(26.7 \%)$ \\
Preoperative laboratory data & \\
Hemoglobin $(\mathrm{g} / \mathrm{dL})$ & $13.3 \pm 1.3$ \\
Albumin $(\mathrm{g} / \mathrm{dL})$ & $4.0 \pm 0.3$ \\
Prealbumin $(\mathrm{mg} / \mathrm{dL})$ & $27.8 \pm 6.3$ \\
\hline
\end{tabular}

Values are given as either the mean $\pm \mathrm{SD}$, the median (with the range in brackets), or as the number of patients with percentages in parentheses

$T L P P G$ totally laparoscopic pylorus-preserving gastrectomy, ASA-PS American Society of Anesthesiologists physical status, ESD endoscopic submucosal dissection

shown in Table 2. The mean operation time $( \pm \mathrm{SD})$ was $259 \pm 43$ min with a mean blood loss $( \pm$ SD) of $28 \pm 31 \mathrm{~mL}$. The hepatic branch of the vagus nerve was preserved in all patients. In all patients, the TLPPG procedure was performed successfully, with no conversion to open surgery. No patient had a cancer-positive margin. The postoperative pathological examination confirmed $\mathrm{T} 1$ in 55 patients and $\mathrm{T} 2$ in 5 patients. Nodal metastasis was observed in 6 patients; $\mathrm{N} 1$ in 4 and $\mathrm{N} 2$ in 2 according to the Japanese classification of gastric carcinoma [19].

Twelve patients $(20.0 \%)$ experienced postoperative complications classified as grade II using the ClavienDindo classification (Table 3) [20]. The most frequent complication was gastric stasis (6 cases, $10.0 \%$ ), which was defined when the following conditions were fulfilled: upper abdominal distension, remnant stomach fullness on radiography image, and a period of starvation longer than $24 \mathrm{~h}$. Four patients $(6.7 \%)$ had an abdominal fluid collection including pancreatic fistula. There were no grade III complications, but one patient $(1.7 \%)$ with postoperative intra-abdominal bleeding who required blood transfusion, angiography, reoperation and intensive treatment was classified as grade IVb. The median postoperative hospital stay (range) was 11 (8-256) days.

\section{Discussion}

Sixty consecutive TLPPG patients were examined in this study, a much larger number than the previous report, which consisted of 12 TLPPG and 13 laparoscopic segmental gastrectomies [17]. PPG and segmental gastrectomy are different operations because PPG requires retrieval of station 6 lymph node and dissection of the right 
Table 2 Operative and postoperative data from patients undergoing TLPPG $(n=60)$

\begin{tabular}{ll}
\hline Operation time (min) & $259 \pm 43$ \\
Blood loss (mL) & $28 \pm 31$ \\
Retrieved lymph nodes & $45 \pm 13$ \\
Preservation of the vagus nerve & \\
$\quad$ Hepatic branch only & 21 \\
Hepatic branch and celiac branch & 39 \\
T factor (T1a/T1b/T2) & $35 / 20 / 5$ \\
N factor (N0/N1/N2) & $54 / 4 / 2$ \\
Proximal margin (cm) & $4.0 \pm 1.9$ \\
Distal margin (cm) & $3.6 \pm 2.2$ \\
Time until start of flatus (days) & $2.2 \pm 0.8$ \\
Median postoperative hospital stay (days) & $11[8-256]$ \\
\hline
\end{tabular}

Values are given as either the mean $\pm \mathrm{SD}$, the median with the range in brackets, or as the number of patients

$T L P P G$ totally laparoscopic pylorus-preserving gastrectomy

Table 3 Postoperative complications classified as grade II or above using the Clavien-Dindo grading system in patients undergoing TLPPG $(n=60)$

\begin{tabular}{ll}
\hline Grade II & $12(20.0)$ \\
Stasis & $6(10.0)$ \\
Abdominal fluid collection & $4(6.7)$ \\
Fever of unknown origin & $1(1.7)$ \\
Enteritis & $1(1.7)$ \\
Grade IVb & $1(1.7)$ \\
Intra-abdominal bleeding & $1(1.7)$ \\
\hline
\end{tabular}

Data show the number of patients with percentages in parentheses

$T L P P G$ totally laparoscopic pylorus-preserving gastrectomy

gastroepiploic artery and vein as close to their roots. Those differences should affect the postoperative outcome, including gastric stasis.

The incidence of severe postoperative complications classified as grade III or above was $1.7 \%$, which was acceptable, considering we performed radical lymphadenectomy for all patients. Postoperative gastric stasis was the most frequent complication, occurring in $10.0 \%$ of patients. Although the pathophysiological mechanism of gastric stasis is not totally clear, the length of the pyloric cuff is reported to influence postoperative gastric stasis [21]. There is a risk of dissecting the posterior wall of the antrum and shortening the pyloric cuff when creating a delta-shaped intracorporeal gastrogastrostomy using linear staplers. This might affect the occurrence of postoperative gastric stasis. The observed relatively high incidence of gastric stasis may be due to the lack of experience for the particular technique. This was also indicated in our previous study on LAPPG where surgical experience was a significant factor for lower incidence of postoperative complications [9]. Thus, the results may improve by standardization of the procedure. Further investigation is required to clarify the influence of the intracorporeal deltashaped gastrogastrostomy on postoperative gastric stasis after standardization of the procedure.

The oncological safety of the TLPPG procedure is another issue that should be examined, and no positive margin was observed in this study. Confirming the location of early tumors in a totally laparoscopic procedure is quite difficult, and therefore oncological safety in this procedure is ensured by the preoperative placement of marking clips and intraoperative gastroscopy.

The operation time for TLPPG was approximately 30 min longer than the previously reported operation time for LAPPG [9]. It is most likely that the longer operation times recorded for TLPPG in this study were due to the necessity of performing an intraoperative gastroscopy in all cases to determine the resection line for the stomach, whereas the location of the tumor is verified easily in the LAPPG procedure by palpating preoperatively placed marking clips.

In summary, TLPPG with an intracorporeal delta-shaped gastrogastrostomy was found to be a safe procedure, although it tended to require a longer operating time than LAPPG with a hand-sewn gastrogastrostomy.

Acknowledgments The authors would like to thank Dr. Ioannis Rouvelas from Karolinska University Hospital, Sweden for revising the manuscript. We also thank Mr. Shigeyuki Sakaguchi for preparing the figures in this manuscript.

\section{References}

1. Kunisaki C, Ishino J, Nakajima S, Motohashi H, Akiyama H, Nomura M, et al. Outcomes of mass screening for gastric carcinoma. Ann Surg Oncol. 2006;13:221-8.

2. Tashiro A, Sano M, Kinameri K, Fujita K, Takeuchi Y. Comparing mass screening techniques for gastric cancer in Japan. World J Gastroenterol. 2006;12:4873-4.

3. Shimoyama S, Mafune K, Kaminishi M. Indications for a pylorus-preserving gastrectomy for gastric cancer with proper muscle invasion. Arch Surg. 2003;138:1235-9.

4. Imada T, Rino Y, Takahashi M, Suzuki M, Tanaka J, Shiozawa $\mathrm{M}$, et al. Postoperative functional evaluation of pylorus-preserving gastrectomy for early gastric cancer compared with conventional distal gastrectomy. Surgery. 1998;123:165-70.

5. Nishikawa K, Kawahara H, Yumiba T, Nishida T, Inoue Y, Ito T, et al. Functional characteristics of the pylorus in patients undergoing pylorus-preserving gastrectomy for early gastric cancer. Surgery. 2002;131:613-24.

6. Zhang D, Shimoyama S, Kaminishi M. Feasibility of pyloruspreserving gastrectomy with a wider scope of lymphadenectomy. Arch Surg. 1998;133:993-7.

7. Horiuchi T, Shimomatsuya T, Chiba Y. Laparoscopically assisted pylorus-preserving gastrectomy. Surg Endosc. 2001;15:325-8.

8. Jiang X, Hiki N, Nunobe S, Fukunaga T, Kumagai K, Nohara K, et al. Long-term outcome and survival with laparoscopy-assisted 
pylorus-preserving gastrectomy for early gastric cancer. Surg Endosc. 2011;25:1182-6.

9. Jiang X, Hiki N, Nunobe S, Fukunaga T, Kumagai K, Nohara K, et al. Postoperative outcomes and complications after laparoscopy-assisted pylorus-preserving gastrectomy for early gastric cancer. Ann Surg. 2011;253:928-33.

10. Shinohara H, Sonoda T, Niki M, Nomura E, Nishiguchi K, Tanigawa N. Laparoscopically-assisted pylorus-preserving gastrectomy with preservation of the vagus nerve. Eur J Surg. 2002; 168:55-8.

11. Urushihara T, Sumimoto K, Shimokado K, Kuroda Y. Gastric motility after laparoscopically assisted distal gastrectomy, with or without preservation of the pylorus, for early gastric cancer, as assessed by digital dynamic $\mathrm{x}$-ray imaging. Surg Endosc. 2004; 18:964-8.

12. Uyama I, Sugioka A, Fujita J, Komori Y, Matsui H, Soga R, et al. Purely laparoscopic pylorus-preserving gastrectomy with extraperigastric lymphadenectomy for early gastric cancer: a case and technical report. Surg Laparosc Endosc Percutan Tech. 1999;9:418-22.

13. Kanaya S, Gomi T, Momoi H, Tamaki N, Isobe H, Katayama $\mathrm{T}$, et al. Delta-shaped anastomosis in totally laparoscopic Billroth I gastrectomy: new technique of intraabdominal gastroduodenostomy. J Am Coll Surg. 2002;195:284-7.

14. Kim JJ, Song KY, Chin HM, Kim W, Jeon HM, Park CH, et al. Totally laparoscopic gastrectomy with various types of intracorporeal anastomosis using laparoscopic linear staplers: preliminary experience. Surg Endosc. 2008;22:436-42.

15. Uyama I, Sugioka A, Fujita J, Komori Y, Matsui H, Soga R, et al. Completely laparoscopic extraperigastric lymph node dissection for gastric malignancies located in the middle or lower third of the stomach. Gastric Cancer. 1999;2:186-90.

16. Song KY, Park CH, Kang HC, Kim JJ, Park SM, Jun KH, et al. Is totally laparoscopic gastrectomy less invasive than laparoscopyassisted gastrectomy? Prospective, multicenter study. J Gastrointest Surg. 2008;12:1015-21.

17. Lee SW, Bouras G, Nomura E, Yoshinaka R, Tokuhara T, Nitta $\mathrm{T}$, et al. Intracorporeal stapled anastomosis following laparoscopic segmental gastrectomy for gastric cancer: technical report and surgical outcomes. Surg Endosc. 2010;24:1774-80.

18. Hiki N, Kaminishi M. Pylorus-preserving gastrectomy in gastric cancer surgery-open and laparoscopic approaches. Langenbecks Arch Surg. 2005;390:442-7.

19. Japanese classification of gastric carcinoma: 3rd English edition. Gastric Cancer. 2011;14:101-12.

20. Dindo D, Demartines N, Clavien PA. Classification of surgical complications: a new proposal with evaluation in a cohort of 6336 patients and results of a survey. Ann Surg. 2004;240: 205-13.

21. Nakane Y, Michiura T, Inoue K, Sato M, Nakai K, Yamamichi K. Length of the antral segment in pylorus-preserving gastrectomy. Br J Surg. 2002;89:220-4. 